\title{
(t)
}

\section{POLÍTICA AGRÁRIA: EXTENSÃO RURAL E SERVIÇO SOCIAL, A EQUAÇÃO POSSÍVEL}

\author{
AGRARIAN POLICY: RURAL EXTENSION AND \\ SOCIAL SERVICE, THE POSSIBLE EQUATION
}

\section{Amanda Farias dos Santos ${ }^{1}$ Mailiz Garibotti Lusa²}

\section{RESUMO}

Este artigo trata do exercício profissional do Serviço Social na Política Nacional de Assistência Técnica e Extensão Rural (PNATER), discutindo suas competências e atribuições. Visa ampliar o olhar acerca das possibilidades da política e da atuação do/a assistente social no campo. Com abordagem qualitativa, utilizou-se da pesquisa bibliográfica e documental, além de valer-se das experiências adquiridas nesse espaço sócio-ocupacional. O trabalho versa sobre a Assistência Técnica e Extensão Rural no Brasil; o capitalismo no campo e a classe trabalhadora rural; o Projeto Ético-Político da profissão, bem como sobre as competências e atribuições do Serviço Social na ATER. Finalizando, indica-se a perspectiva de atuação do/a assistente social em várias linhas de atuação da política.

Palavras-chave: Assistência Técnica e Extensão Rural. Capitalismo no Campo. Classe Trabalhadora Rural. Serviço Social.

\section{ABSTRACT}

This article deals with social service professional practice in the National Policy on Technical Assistance and Rural Extension (PNATER), discussing

1 Assistente Social (Extensionista Rural) do Instituto de Inovação para o Desenvolvimento Rural Sustentável de Alagoas - EMATER/AL. E-mail: amanda.social@hotmail.com

2 Professora Adjunta - Curso de Serviço Social da UFAL/AL. E-mail: mailizlus@yahoo.com.br 


\section{tempordils}

its competences and attributions. It aims to broaden perspectives on the possibilities of social worker policy and action in the countryside. With a qualitative approach, we used the bibliographical and documentary research, in addition to experiences in this socio-occupational space. The work is about Technical Assistance and Rural Extension in Brazil; capitalism in the countryside and rural working class; the Ethical-Political Project of the profession, as well as the competences and attributions of Social Service in ATER. Finally, we indicate social workers acting perspective in various policy lines of activity.

Keywords: Technical Assistance and Rural Extension. Capitalism in the Countryside. Rural Working Class. Social Service.

Submetido em 25/03/2014

Aceito em 17/09/2014

\section{INTRODUÇÃO}

O interesse pelo objeto "Serviço Social na Assistência Técnica e Extensão Rural" decorreu do fato de as experiências profissionais dessa autora terem sido nesse espaço sócio-ocupacional: a primeira se deu com a sua inserção na Secretaria de Estado da Agricultura e Desenvolvimento Agrário (SEAGRI/AL); a segunda, através do Centro de Capacitação Zumbi dos Palmares³; e a terceira, e atual, realiza-se no Instituto de Inovação para o Desenvolvimento Rural Sustentável de Alagoas (EMATER/AL)4

O objetivo desta pesquisa consiste em analisar a Política Nacional de Assistência Técnica e Extensão Rural (PNATER) e o Projeto Ético-Político do Serviço Social, tratando, em particular, da intervenção do Serviço Social na Assistência Técnica e Extensão Rural (ATER). O problema proposto incide em responder quais as competências e atribuições da profissão nesse âmbito, de forma a identificá-las.

A ATER brasileira, de acordo com Cazella, Kreutz e Pinheiro (2005), passou por três fases em relação a seu processo

3 Realizou-se com a execução do Projeto Básico de Assistência Técnica e Extensão Rural do Instituto de Colonização e Reforma Agrária - INCRA/AL, através da Chamada Pública de ATER n. 01/2012 - INCRA SR 22.

4 Execução da Chamada Pública de ATER n. 10/2012, Lote 4, do Ministério do Desenvolvimento Agrário (MDA), que tem como finalidade colaborar na promoção da sustentabilidade familiar. Bolsa adquirida através de seleção de vaga/s ofertada/s pelo Edital FAPEAL/SEAGRI n. 008/2013. 
pedagógico: a primeira origina-se na década de 1950, período em que acontece a organização dos serviços de extensão rural oficial no Brasil, com ações educativas tradicionais, que deveriam envolver o agricultor com o padrão de produção e consumo hegemônicos dependentes de insumos externos. A segunda, que se inicia nos anos 1960 e tem a predominância de um trabalho guiado pelos moldes fordistas (mecânico, segmentado rotineiro), presencia uma forma difusionista e guiada por uma pedagogia tecnicista, em que a ATER detém o controle científico. E, finalmente, a terceira fase, que se inicia nos anos 1980 quando é percebido que o modelo de desenvolvimento agrícola, até então implantado, está em crise e que se faz necessário buscar novas alternativas de se fazer a extensão rural.

No entanto, as transformações sociais, políticas, econômicas e culturais sofridas pelo Brasil rural afetaram diretamente não somente o espaço físico do campo como também a vida da classe trabalhadora rural, e, consequentemente, a atuação da ATER, que passa a se basear na Política Nacional de Assistência Técnica e Extensão Rural (PNATER).

Portanto, para entender o Serviço Social na ATER, este trabalho está estruturado em quatro seções: a primeira aborda brevemente o rural e traça a trajetória da ATER até a implantação de sua nova política; a segunda trata do capitalismo no campo e identifica a classe trabalhadora rural; a terceira contempla o processo de formação do Projeto Ético-Político do Serviço Social, que propiciou a profissão a adotar as dimensões ético-política, teórico-metodológica e técnico-operativa que vão ao encontro de uma nova ordem societária. O estudo finaliza-se com a quarta seção, a qual apresenta as competências e atribuições privativas do/a assistente social, enquanto extensionista rural.

Posto isso, conclui-se que o/a assistente social na ATER não possui somente a competência de assistir cooperativas, associações, grupos produtivos de mulheres e execução das políticas públicas específicas para a agricultura; a formação generalista desse/a profissional lhe permite atuar em diversas linhas, as quais serão apresentadas a seguir. 


\section{temporalis}

\section{DO BRASIL AGRÁRIO À ASSISTÊNCIA TÉCNICA E EXTENSÃO RURAL}

Consolidada no cultivo da cana-de-açúcar e iniciada através das capitanias hereditárias, a agricultura brasileira originou-se no período de colonização e permanece baseada na monocultura realizada em latifúndios.

Não somente o cultivo da cana-de-açúcar como também o do café e de outras culturas, além da agropecuária e das práticas extrativistas que foram desenvolvidas desde a colonização, influenciaram em fatores sociais, culturais, econômicos e políticos. Vale lembrar que a base desse tipo de exploração das riquezas foi escravocrata e teve como primeiros sujeitos os indígenas, que resistiram a tal situação, e, posteriormente, os negros, que foram privados de sua liberdade.

Uma das consequências mais visíveis desse período trata-se da concentração da propriedade de terras nas mãos de uma pequena parcela da sociedade. "É esse fator um dos principais fundamentos das desigualdades da nação: a apropriação e concentração, embora oficial, mas indevida, de terras, associada aos diversos ciclos de exploração das riquezas [...]" (LUSA, 2012, p. 35).

Embora a sociedade contemporânea tenha sido marcada durante diferentes períodos pelo rural e esse se destaque na economia brasileira, observa-se, como bem afirma Lusa (2012), que no âmbito social e político o rural parece continuar invisibilizado pelo Estado e pela sociedade. Para melhor compreender como ocorre essa invisibilidade por parte do Estado e da sociedade, faz-se necessário discorrer a respeito das políticas públicas voltadas à agricultura, mais precisamente as que dizem respeito aos serviços de ATER, por se tratar do objeto de estudo.

Os serviços de extensão rural não são contemporâneos; suas primeiras ações foram desenvolvidas na antiguidade, mas esse termo originou-se durante a extensão executada pelas universidades inglesas, na segunda metade do século XIX. O século XX trouxe a criação do serviço cooperativo de extensão rural dos Estados Unidos, que concretizou, pela primeira vez, uma forma institucionalizada de extensão rural (PEIXOTO, 2008). 
De acordo com Peixoto (2008), os termos "assistência técnica" e "extensão rural" diferem-se pelo fato de que, enquanto esse se trata de um processo educativo de comunicação de conhecimentos de diversas naturezas, aquele não possui, necessariamente, um caráter educativo, visto que seu intuito seria o de resolver problemas específicos, pontuais, sem nenhum tipo de capacitação. Para ele, a extensão rural pode ser vista como processo, instituição/organização e política pública.

A extensão rural como processo, literalmente falando, é o ato de transmitir conhecimentos ao público rural ou, em relação ao sentido mais amplo e aceito, é um processo educativo de comunicação de conhecimentos técnicos ou não. Utiliza métodos pedagógicos e os tradicionais são: individuais (visitas, unidade de observação etc.), grupais (reuniões, unidade demonstrativa, dia de campo etc.) e de massa (feira, concurso etc.). Já em relação à extensão rural como instituição/organização, essa se refere aos serviços de ATER desenvolvidos por instituições públicas. Assim, pode-se citar como exemplo as EMATERs 5 . Quanto ao terceiro sentido, a extensão rural como política pública, corresponde às políticas de extensão rural tanto dos governos federais quanto dos estaduais e municipais, executadas por organizações públicas e privadas.

A ATER no Brasil teve suas primeiras experiências no final da década de 1940 e expandiu-se na década de 1950. Observa-se então a criação das Associações de Crédito e Assistência Rural (ACAR), que foram coordenadas pela Associação Brasileira de Crédito e Assistência Rural ( $A B C A R$ ).

A década de 1960 não trouxe novidades: os serviços de ATER continuaram sendo implantados no país através das ACARs e a assistência aos/às agricultores/as não tinha como objetivo colaborar com a qualidade de vida desses/as, mas sim fortalecer o desenvolvimento industrial.

O método de ação das ACARs foi inspirado no modelo norte-americano de extensão rural, mas

5 No caso de Alagoas, foi “recriada" através da Lei n. 7.291, de 01 de dezembro de 2011, e publicada no Diário Oficial do Estado com a denominação de Instituto de Inovação para o Desenvolvimento Rural Sustentável. 


\section{temporalis}

os serviços não eram prestados diretamente por universidades, e sim pelas associações. Todavia, o crédito supervisionado por um serviço de assistência técnica foi uma inovação no modelo brasileiro que estava sendo implantado, uma vez que nos EUA os produtores rurais já estavam habituados a relacionar-se com os bancos e obter empréstimos (PEIXOTO, 2008, p. 18).

Durante a década de 1970, os serviços de ATER tornaram-se públicos e cabia ao Governo Federal a responsabilidade sobre eles. O Sistema Brasileiro de Assistência Técnica e Extensão Rural (SIBRATER) foi criado em 1974 e tinha a Empresa Brasileira de Assistência Técnica e Extensão Rural (EMBRATER) como coordenadora.

O objetivo da ATER era apoiar o processo de modernização da agricultura, contribuindo, dessa forma, com o projeto de desenvolvimento do capitalismo no campo, através da chamada Revolução Verde ${ }^{6}$.

No entanto, suas práticas eram difusionistas e os extensionistas rurais (em sua maioria engenheiros agrônomos e técnicos agropecuários, que assistiam os agricultores no âmbito da produção) e os extensionistas sociais ${ }^{7}$ (geralmente professoras e economistas domésticas, que assistiam as mulheres dos agricultores em relação ao ambiente doméstico) eram somente transmissores/as de informações; os/as agricultores/as, mesmo sendo os/as

6 Tratou-se de um pacote tecnológico que prometia inovar a agricultura através da adoção de sementes, fertilizantes e inseticidas; sua disseminação se deu através da lógica da produção monocultora nas terras de grande extensão e por meio do crédito barato e de fácil acesso que fora intensificado no Brasil no início dos anos 1970. Vale ressaltar que a maioria dos pequenos agricultores não teve acesso a essas técnicas de caráter produtivista.

7 Os termos extensionista rural e extensionista social ainda são adotados por alguns. Assim, pode-se observar em textos, editais e/ou seleções de profissionais da ATER, o uso desses termos para distinguir os profissionais das Ciências Biológicas dos das Ciências Humanas e Ciências Sociais Aplicadas. Contudo, como todos/as os/as agentes de ATER estão inseridos/as no rural e suas ações são voltadas para os sujeitos do campo, acredita-se que todos/as devem ser denominados/as de extensionistas rurais. Portanto, a partir desse pensamento, o texto adotará a denominação extensionista rural para se referir a todos/as os/ as profissionais desse âmbito. Vale também salientar que é comum que esses/as sejam abordados/as como "o/a extensionista rural" e não como "o/a assistente social”, o/a nutricionista etc. 
principais conhecedores/as da realidade local, não participavam do processo de escolhas de intervenção e eram meros/as receptores/as de informações.

A Assistência Técnica e Extensão Rural brasileira, até então, havia passado por impasses, mas não tão graves quanto o enfrentado na década de 1990: durante a transição do governo Sarney para o Collor de Mello, foi extinta a EMBRATER e, consequentemente, desativado o SIBRATER. Por meio do Decreto n. 97.455/89, o governo Sarney extinguiu a EMBRATER e outras estatais. Contudo, a mobilização política do setor extensionista e dos/as produtores/as rurais obteve uma resposta positiva do Congresso, que, através do Decreto Legislativo n. 3, de 05 de abril de 1989, foi aprovado e, com ele, foi sustada a dissolução da EMBRATER, da Empresa Brasileira de Transportes Urbanos (EBTU) e da Empresa Brasileira de Planejamento de Transporte (GEIPOT). No entanto, o que não se esperava era que o próximo governo iria executar tal ideia: no governo de Fernando Collor de Mello, o Decreto n. 99.192, de 15 de março de 1990, extinguiu definitivamente a EMBRATER e outras estatais.

Mesmo tendo protegido pela Constituição Federal de 1988 e pela Lei Agrícola, de n. 8.171/91, o direito de receber a prestação de serviços de ATER pública e gratuita, os/as agricultores/ as ficaram sem a assistência de um órgão público dessa área. Percebe-se, assim, que a ATER, apesar de voltar-se para as questões das elites agrárias, não foi poupada das políticas neoliberais e que os esforços realizados anteriormente foram de vez abandonados por parte do Estado.

Contudo, apesar da falta de apoio do Governo Federal, alguns estados conseguiram estruturar os seus serviços de ATER, em que foram não somente criados novos mecanismos de financiamento e operacionalização das empresas oficiais, como também implantadas várias iniciativas desses serviços através de organizações não governamentais e de organizações de agricultores/as.

A consequência desse processo de afastamento do Estado e da diminuição da oferta de serviços públicos da ATER ao meio rural evidencia-se hoje, pela comprovada insuficiência destes serviços em 


\section{temporolis}

atender a demanda da agricultura familiar e dos demais povos que vivem e exercem atividades produtivas no meio rural, principalmente nas áreas de maior necessidade, como as Regiões Norte e Nordeste. Com isso, restringem-se as possibilidades de acesso das famílias e coletivos rurais ao conhecimento, aos resultados da pesquisa agropecuária e a políticas públicas em geral, o que contribui para ampliar as desigualdades sociais no campo (MDA, 2004 p. 5).

A Assistência Técnica e Extensão Rural na década de 1990 ficou fragilizada, no entanto destaca-se que em 1996 é formulado pelo Ministério do Desenvolvimento Agrário (MDA) o Projeto Lumiar, o qual pretendia promover os serviços de ATER aos/às assentados/as da Reforma Agrária no país. Executado pelo INCRA, "o desenho institucional previsto pelo Lumiar reunia governo, movimentos sindicais e sociais de trabalhadores rurais, associações de trabalhadores rurais, universidades e cooperativas de técnicos", que tinham como objetivo promover o desenvolvimento rural e a melhoria da qualidade de vida da agricultura familiar. $\mathrm{O}$ Lumiar pode ser considerado como inovador por "privilegiar a gestão do trabalho de produção e controle da intervenção, por parte das próprias famílias assentadas. Contrário, portanto, à história de submissão que tem orientado outras ações públicas de apoio às populações rurais" (GALINDO, 2003, p. 59).

Posteriormente, os serviços de ATER ofertados pelo INCRA para os assentamentos passaram a ser através do Programa de Assessoria Técnica, Social e Ambiental à Reforma Agrária (ATES), que possuía o mesmo perfil do Projeto Lumiar; ou melhor, "quatro anos após seu abrupto encerramento, em consequência de denúncias sobre desvios de recursos, o Projeto Lumiar renasce revisto e atualizado - na proposta de institucionalização dos serviços de ATES defendida pelo INCRA" (DIAS, 2004, p. 516).

Atualmente, os serviços ofertados pelo INCRA aos assentamentos são prestados por intermédio de chamadas públicas, as quais já possuem em seus projetos básicos as atividades e ações a serem realizadas através de metas. Diante disso, fazem-se as seguintes indagações: será que esses projetos são elaborados de acordo com a realidade local e com as demandas de seus/suas 
usuários/as? E as metas direcionadas a certo/a profissional, será que estão mesmo de acordo com as atribuições dele/a? E quanto aos/às técnicos/as do INCRA que elaboram esses projetos, será que possuem uma formação generalista? Será que durante essas elaborações há a participação de profissionais tanto da área da agronomia quanto da social, ambiental, ou das diversas áreas afins? E no tocante à participação dos/as usuários/as, será que esses/as são questionados/as quanto as suas demandas e expectativas em relação a ATER? Há muito que se pensar a respeito do tipo de Assistência Técnica e Extensão Rural que está sendo ofertado, pois há o risco de se estar indo de encontro à realidade social.

A PNATER, elaborada e aprovada em 2003, "nasce a partir da análise crítica dos resultados negativos da Revolução Verde e dos problemas já evidenciados pelos estudos dos modelos convencionais de ATER baseados no difusionismo [...]" (MDA, 2004, p. 3). Contudo, vale salientar que essa não se manteve de acordo com sua primeira versão ${ }^{8}$, ao ser instituída pela Lei 12.188, de 11 de janeiro de 2010.

Assim, ela estabelece alguns conceitos relevantes (ATER, Declaração de Aptidão ao Programa Nacional de Fortalecimento da Agricultura Familiar - DAP e Relação de Beneficiários - RB), além de trazer os princípios e objetivos da ATER, de apresentar os/as seus/suas beneficiários/as e o Programa Nacional de Assistência Técnica e Extensão Rural (PRONATER), dentre outros quesitos.

O Art. $3^{\circ}$ dessa política contempla seis princípios que tratam do desenvolvimento rural sustentável; dos serviços de ATER gratuitos, acessíveis e de qualidade; da adoção de metodologia participativa e do trabalho multidisciplinar, interdisciplinar e intercultural; da agricultura de base ecológica; da equidade nas

8 Para melhor compreender a diferença entre a PNATER elaborada, em 2003, por organizações governamentais e não governamentais e por organizações de representação da agricultura familiar e a PNATER que fora instituída em 2010, pela Presidência da República, ler CAPORAL, F. R. Lei de ATER: Exclusão da Agroecologia e outras armadilhas, 2011. Disponível em: <http://www.abaagroecologia.org.br/ revistas/index.php/cad/article/viewFile/11858/8174>.

Acesso em: 27 fev. 2014. 


\section{temporalis}

relações de gênero, geração, raça e etnia; bem como da segurança alimentar e nutricional. No que concerne aos objetivos, são trazidos no Art. $4^{\circ}$ e estão relacionados às seguintes temáticas: desenvolvimento rural sustentável; iniciativas econômicas; aumento da produção, qualidade e produtividade das atividades e serviços; qualidade de vida; realização de assessoria; ações voltadas ao uso, manejo, proteção, conservação e recuperação dos recursos naturais; sistemas de produção sustentável; renda do público beneficiário; associativismo e cooperativismo; desenvolvimento e apropriação da produção de inovações tecnológicas e organizativas; integração da ATER com a pesquisa e expansão do aprendizado e da qualificação profissional e diversificada (BRASIL, 2010).

De acordo com os Artigos $6^{\circ}$ e $7^{\circ}$, o PRONATER, além de ter sido instituído como principal instrumento de implementação da PNATER, tem como objetivos a organização e a execução dos serviços de ATER aos/as usuários/as (BRASIL, 2010).

O meio rural revela como atores sociais os grandes proprietários rurais, os agricultores familiares, as famílias sem terra e demais segmentos. Porém, destaca-se, aqui, que a PNATER define como seus/as beneficiários/as os/as assentados/as da reforma agrária, os povos indígenas, os remanescentes de quilombos e demais povos de comunidades tradicionais. Essa política também propõe que sejam desenvolvidas ações que garantam ATER também para as mulheres do campo, ao defender como um de seus princípios a equidade nas relações de gênero, geração, raça e etnia.

É válido ressaltar que a criação dessa política tratou-se da resposta dada à luta de agricultores/as familiares (incluindo-se assentados/as da Reforma Agrária, remanescentes de quilombolas, índios/as, pescadores/as etc.) por uma ATER pública, bem como de movimentos sociais, extensionistas rurais, sindicatos etc. Conforme o Decreto n. 4.739, de 13 de junho de 2003, o Ministério do Desenvolvimento Agrário (MDA) passou a se responsabilizar pelos serviços de ATER. "Este processo, democrático e participativo que envolveu mais de 100 entidades e mais de 500 
pessoas, levou à construção de alguns consensos e a um conjunto de acordos [...]" (CAPORAL, 2005, p. 1).

A efetivação dessa política assim como a ampliação dos serviços de ATER tornam-se relevantes, pois, como bem afirma Peixoto (2008, p.8), "frequentemente encontrarmos textos dizendo, por exemplo, que 'a extensão rural desempenha nos estados um papel importante no processo de desenvolvimento dos pequenos produtores"”.

Conhecida como Lei de ATER, essa política foi criada e instituída no governo Lula e trouxe a ideia de que os serviços desse âmbito iriam passar por uma fase de valorização do governo. Essa ideia foi percebida através das palavras do ex-ministro de Desenvolvimento Agrário, Guilherme Cassel, que, em 2010, afirma: "estamos iniciando um segundo ciclo de ATER no País. Saltamos de um orçamento de R\$ 42 milhões em 2003 para R\$ 626 milhões em 2010, totalizando R\$2,2 bilhões". No entanto, não se deve deixar-se impressionar com números e com o fato de esse governo ter um caráter populista. A PNATER, bem como as demais políticas públicas, permaneceu fragmentada e compensatória, e seus serviços são, em grande parte, pontuais e descontínuos.

A PNATER define ATER como sendo um serviço de educação não formal, de caráter continuado, que promove processos de gestão, produção, beneficiamento e comercialização das atividades e dos serviços agropecuários e não agropecuário, e afirma que seus extensionistas rurais devem adotar metodologias participativas, focando na realidade e no conhecimento local. "A educação não formal, ao contrário, não é herdada, é adquirida. Ela capacita os indivíduos a se tornarem cidadãos do mundo, no mundo. Sua finalidade é abrir janelas de conhecimento sobre o mundo que circunda os indivíduos e suas relações sociais" (GOHN, 2010, p. 19).

A Assistência Técnica e Extensão Rural, a partir daí, ganha uma nova cara: suas ações e atividades voltam-se para uma metodologia participativa e de acordo com a realidade e o conhecimento local; suas equipes técnicas se diversificam e aos poucos vão se inserindo outros profissionais (assistentes sociais, nutricionistas, engenheiros/as florestais, veterinários/as, zootecnistas etc.). Agora, o/a extensionista rural deve assumir a posição de 


\section{temporalis}

educador/a não formal, colaborando na identificação de problemas e no planejamento da sua solução. Aqui também se destaca a importância do trabalho interdisciplinar que pode ser desenvolvido, já que agora há a presença de vários saberes.

A interdisciplinaridade sugere a identificação de uma problemática comum e o levantamento de uma política básica. Através da adoção de uma plataforma de trabalho conjunto, serão postos os princípios e os conceitos fundamentais, bem como suas diferenças e convergências, no intuito de gerar uma aprendizagem mútua, uma recombinação de elementos internos. Em outras palavras, o desenvolvimento de ações interdisciplinares tende a horizontalizar as relações de poder entre os campos envolvidos (VASCONCELOS, 1997, p. 141). "Logo, a riqueza da nova ATER está na sua capacidade criativa [...]". "A compreensão da realidade deve ser buscada junto com as comunidades de agricultores, o que permite a definição de estratégias apropriadas ao contexto de cada comunidade, salvaguardando-se os princípios da PNATER" (CAPORAL; RAMOS, 2006, p. 8).

Contudo, ao analisar-se essa política nova de ATER, bem como os projetos de chamadas públicas e mesmo alguns serviços que são desenvolvidos pelas instituições executoras, observa-se que estes focam na questão produtiva e na geração de renda dos/ as agricultores/as assistidos/as. Percebe-se, portanto, que ainda há um pensamento voltado para uma perspectiva desenvolvimentista. A maioria dos objetivos da PNATER, trazidos em seu Art. $4^{\circ}$, confirma isso:

I - promover o desenvolvimento rural sustentável; II - apoiar iniciativas econômicas que promovam as potencialidades e vocações regionais e locais; III aumentar a produção, a qualidade e a produtividade das atividades e serviços agropecuários e não agropecuários, inclusive agroextrativistas, florestais e artesanais; IV - promover a melhoria da qualidade de vida de seus beneficiários; V - assessorar as diversas fases das atividades econômicas, a gestão de negócios, sua organização, a produção, inserção no mercado e abastecimento, observando as peculiaridades das diferentes cadeias produtivas; VI - desenvolver ações voltadas ao uso, manejo, proteção, 
conservação e recuperação dos recursos naturais, dos agroecossistemas e da biodiversidade; VII construir sistemas de produção sustentáveis a partir do conhecimento científico, empírico e tradicional; VIII - aumentar a renda do público beneficiário e agregar valor a sua produção; IX - apoiar o associativismo e o cooperativismo, bem como a formação de agentes de assistência técnica e extensão rural; $X$ - promover o desenvolvimento e a apropriação de inovações tecnológicas e organizativas adequadas ao público beneficiário e a integração deste ao mercado produtivo nacional; XI - promover a integração da ATER com a pesquisa, aproximando a produção agrícola e o meio rural do conhecimento científico; e XII - contribuir para a expansão do aprendizado e da qualificação profissional e diversificada, apropriada e contextualizada à realidade do meio rural brasileiro (BRASIL, 2010, p. 2, grifo nosso).

O uso de expressões e da adoção de objetivos de cunho capitalista deve-se, talvez, não somente pela herança deixada pelas práticas de extensão rural desenvolvimentistas, mas também pelo fato de a PNATER originar-se em meio a uma política neoliberal. Há que se considerar que os serviços de ATER foram/ são executados, em grande parte, por profissionais da área da agronomia e que a formação que muitos cursos desse âmbito ofertam a seus/suas profissionais é voltada para o desenvolvimento de trabalhos com grandes produtores rurais.

Diante disso, percebe-se, como bem ressaltam Lusa et al., (2013, p. 124), que os temas voltados para o social se encontram em segundo plano e são considerados de pouca relevância, visto que há a falsa ideia de que o social direciona-se apenas para a população pauperizada e se associa ao assistencialismo e ao amparo a essa população. "Entretanto, sabemos que políticas públicas não são 'favores concedidos', mas antes, direitos conquistados e, sendo assim, não são relativas apenas aos pobres e miseráveis".

É válido ressaltar que a PNATER defende uma prática produtiva agropecuária voltada ao desenvolvimento rural sustentável, à preservação ambiental e à agroecologia. "Nessa perspectiva, a ação extensionista precisa fazer uso de tecnologias e de formas 


\section{temporalis}

de manejo que levem à construção de uma agricultura de base ecológica e, ao mesmo tempo, fortaleçam relações sociais mais equitativas [...]" (CAPORAL, RAMOS, 2006, p. 7). No entanto, há que se considerar a presença de empecilhos que dificultam o uso da agroecologia por parte dos/as agricultores/as familiares: água insuficiente, solos inférteis e o uso tradicional e contínuo de agrotóxicos - que contaminaram os solos e viciaram as culturas - são os maiores.

Visto que há vários impasses e que a PNATER, apesar de trazer avanços, ainda preserva uma ideia desenvolvimentista, afirma-se o quanto é relevante que haja um esforço por parte dos/as gestores/as, dos/as profissionais de ATER e dos/as próprios/as usuários/as para que não apenas as questões relacionadas ao econômico, como também ao social, político e cultural, sejam efetivadas.

\section{CAPITALISMO NO CAMPO: A IDENTIFICAÇÃO DA CLASSE TRABALHADORA RURAL}

De acordo com Engelbrecht (2011, p. 39), os acontecimentos atuais do mundo rural brasileiro se dão graças à expansão do capitalismo no campo, que tem por ordem a acumulação crescente e ampliada. "A tendência do capital é a de tomar conta progressivamente de todos os ramos e setores da produção no campo e na cidade, na agricultura e na indústria". Ela também afirma que a principal particularidade do desenvolvimento das relações capitalistas na agricultura é que o meio de produção fundamental na agricultura, a terra, não é "suscetível de ser reproduzido ao livre arbítrio do homem, como são as máquinas e ou outros meios de produção e instrumentos de trabalho".

A presença do capitalismo no campo brasileiro não é algo concretizado somente na atualidade; como se pode observar, através do próprio estudo feito na seção I deste texto, pode-se identificá-lo durante o final da década de 1970, quando foram implantados pacotes de tecnologias por intermédio da denominada Revolução Verde, ou nos processos produtivos instalados no final do século XIX e início do XX. A promoção da modernização e do desenvolvimento do campo ocorre simplesmente para alcançar os objetivos do capital. 
Em relação aos processos de origem do capitalismo, Gorender (2013, p. 25) aponta para concepções histórico-sociológico-econômicas que propiciaram não somente sua formação no Brasil, como também no campo. Para ele, a primeira trata-se da afirmação de que o capitalismo surgiu a partir do feudalismo e reproduziu, aproximadamente, o processo europeu: "haveria então, até hoje, sobrevivências feudais ou semifeudais no campo brasileiro, as quais seriam obstáculos econômicos e institucionais à penetração do capitalismo na agropecuária nacional".

Já na segunda concepção, o autor expõe a tese de que o capitalismo foi trazido pela colonização portuguesa no século XVI e que enquanto para uns seria um capitalismo incompleto, para outros seria completo e denominado de capitalismo colonial. Como terceira tese, Gorender (2013, p. 25-26) trata da teoria da dependência, ou seja, "até mesmo um modo de produção colonial, como peça do Antigo Sistema, cujo fim ou sentido - sentido tomado na acepção teleológica - seria o de servir à acumulação originária de capital na Europa".

Por fim, é apresentada a tese da origem do capitalismo brasileiro desenvolvido a partir do modo de produção escravista colonial. Essa tese é defendida pelo autor, o qual assegura que se deve considerar o modo de produção escravista colonial (propriedade latifundiária) e o dos pequenos cultivadores não escravistas (pequena propriedade ou pequena posse de terra).

Portanto, diante dos acontecimentos históricos que influenciaram as questões sociais, econômicas, culturais e políticas, afirma-se que a mão de obra, que antes era escravocrata, passa a ser assalariada; "a principal característica da expansão do capitalismo no campo é basicamente os trabalhadores se transformando em trabalhadores livres, isto é, libertos de toda propriedade que não seja a propriedade da sua força de trabalho, da sua capacidade de trabalhar" (ENGELBRECHT, 2011, p. 40).

O rural abarca uma infinidade de sujeitos, os quais podem ser representados na figura dos povos quilombolas, indígenas, assentados, ou mesmo por aqueles que não exercem atividades agrícolas. Destaca-se, aqui, a atenção para aqueles que, diante da concentração fundiária e de todas as problemáticas que esta 


\section{temporalis}

trouxe, desenvolveram uma luta social e política não somente por terra, mas também por condições de vida digna.

Contudo, é válido afirmar que ao mesmo tempo que esse pequeno produtor rural luta contra as amarras do capitalismo, tem suas condições de existência e de sua família, bem como suas necessidades e possibilidades econômicas e sociais, reguladas e controladas pelo capital. "Isto se evidencia de forma bem clara quando a renda tem sido sistematicamente apropriada pelo capital no momento da circulação da mercadoria de origem agrícola e que o pequeno produtor de base familiar está sempre endividado com o banco [...]" (ENGELBRECHT, 2011, p. 43).

A partir dos anos 1990, observa-se, como afirma Lustosa (2012, p. 48-49), uma nova hierarquia na concepção da divisão nacional do trabalho no âmbito rural brasileiro, que vai estabelecer “'novos paradigmas' na leitura das relações sociais, dos processos de trabalho e de produção"; assim, são apresentados dois segmentos sociais heterogêneos que fazem parte da divisão da agricultura: o patronal e o familiar. O modelo patronal e o familiar se distinguem não somente pelo tamanho de suas propriedades, mas também pelas formas de gestão dessas, pelo acesso (ou não) de recursos financeiros e tecnológicos, pelos tipos de culturas desenvolvidas, bem como pelos próprios objetivos que cada um pretende alcançar (LUSTOSA, 2012, p. 49-50).

As políticas públicas que vêm sendo desenvolvidas para a classe trabalhadora rural, não bastassem ser ineficazes, desencadeiam problemáticas como o crescimento da pluriatividade. Um exemplo disso seria "a política de crédito agrícola voltada para os agricultores familiares (PRONAF)", que "deixa de fora os segmentos mais empobrecidos do meio rural", pois a esses é "estimulada à busca por atividades não agrícolas, ou pluriativas" (CRUZ, 2012, p. 257). Portanto, apreende-se que o/a agricultor/a familiar continua sendo assistido/a por uma política agrícola excludente, preocupada apenas com as demandas do mercado e voltada para um modelo modernizador, voltado para a elite. 


\section{PROJETO ÉTICO-POLÍTICO DO SERVIÇO SOCIAL: NOVA ORDEM SOCIETÁRIA}

Como se pode perceber, o espaço rural, assim como o urbano, demanda intervenções sobre as questões sociais. Para entender como se realiza a atuação do Serviço Social nesse âmbito, faz-se relevante o estudo do processo que culminou no atual Projeto Ético-Político da profissão.

Portanto, afirma-se que partir dos anos 1960 o Serviço Social tradicional entra em crise, pois, assim como revela Netto (2007), essa é percebida através da falta de respostas para as solicitações contemporâneas, bem como por meio da formação profissional insuficiente e da subalternidade executiva.

Diante disso, o exercício profissional, que até então se baseava em práticas assistencialistas, ajustadoras e sem uma relação a fundamentos teórico-metodológicos, depara-se com o surgimento, na América Latina, em 1965, do Movimento de Reconceituação. Tal movimento tinha como objetivo desvincular as práticas profissionais do Serviço Social, ainda tradicionais, dos interesses imperialistas e, assim, se opor uma ordem capitalista que é excludente, exploradora e concentradora. Portanto, o Serviço Social brasileiro passou por três vertentes que foram tidas como direções para sua renovação ${ }^{9}$ e que Netto (2007) as denominou como perspectiva modernizadora, de reatualização do conservadorismo e de intenção de ruptura ${ }^{10}$.

Perante esse momento e em meio às condições favoráveis que oferecem o panorama político-social, observa-se que, a partir do final da década de 1970, o movimento operário adquire status como sujeito político. O III Congresso de Assistentes Sociais (IIICBAS), conhecido como Congresso da Virada, que aconteceu em São Paulo, em 1979, retrata bem esse processo: "uma vanguarda profissional virou uma página na história do Serviço Social brasileiro ao destituir a mesa de abertura composta por nomes

9 Vale salientar que o Brasil não fez parte do Movimento de Reconceituação, mas que esse teve grande influência no seu processo de renovação.

10 Diferentemente das demais vertentes, a intenção de ruptura demonstra sintonia com as tendências contestadoras da profissão na América Latina e se aproxima da teoria marxista e das causas da classe trabalhadora. 


\section{temporalis}

oficiais da ditadura, trocando-a por nomes advindos do movimento dos trabalhadores" (BRAZ, 2001, p. 388).

A partir dessa ativa mobilização das vanguardas profissionais na contestação política, da vinculação entre os segmentos mais dinâmicos do corpo profissional e o movimento dos trabaIhadores, constata-se o rompimento com a dominância do conservadorismo e a instauração do pluralismo político na profissão.

Percebe-se, agora, uma nova postura profissional no âmbito do Serviço Social. O Conselho Federal de Assistentes Sociais (CFAS) e os Conselhos Regionais de Assistentes Sociais (CRAS), a partir de 1980, acompanharam o movimento de renovação da profissão, e a diretoria eleita, em 1983, assumiu como principais metas a democratização da entidade, a revisão do novo projeto de regulamentação da profissão e a elaboração de um novo código de ética, estabelecendo o compromisso com as classes populares (BRAVO, 2007, p. 121).

Em relação à formação profissional, a Associação Brasileira de Ensino de Serviço Social (ABESS) demonstrou interesse na reformulação do currículo mínimo do Serviço Social, que se realizou em 1982 e adotou uma visão crítica e voltada para a transformação social. Contudo, apenas uma pequena parcela da categoria se posicionou a favor de um Serviço Social crítico, participativo, voltado às causas da classe trabalhadora e contra a ordem burguesa.

Vale ressaltar que, em fins dos 1970 e início dos 1980, também houve a aproximação do Serviço Social ao marxismo, ainda que de forma fragilizada. De acordo com Netto (1989), essa aproximação se deu através das exigências teóricas muito reduzidas, pela referência seletiva da tradição marxista e mais vinculada a determinadas perspectivas prático-políticas e organizacional-partidárias do que pela sua própria contribuição crítica analítica e, também, devido a sua aproximação por meio de manuais de qualidade e níveis discutíveis.

Segundo Barroco (2006), a militância político-profissional obtém sua maturidade através da organização sindical da categoria, da articulação com a classe trabalhadora e de sua ampliação 
aos demais entes representativos da profissão. Logo, a autora afirma que houve eventos nacionais com temáticas que propiciaram a crítica e a politização, buscando superar os equívocos das tendências presentes no seio da profissão.

Posto isso, afirma-se que são criadas as condições para o surgimento do atual Projeto Ético-Político da Profissão, materializado através do Código de Ética de $1993^{11}$, pela Lei de Regulamentação da profissão e pelas Diretrizes Curriculares para o curso de Serviço Social.

Tal projeto, que tem como valor central a liberdade, estabelece um compromisso com a autonomia, com a emancipação dos indivíduos e, consequentemente, com a justiça social. Logo, propõe a efetivação de um projeto societário que prega uma nova ordem social, sem dominação nem exploração de classe, etnia e gênero, além do compromisso com a defesa intransigente dos direitos humanos e a recusa do arbítrio e de todas as formas de preconceitos, respeitando o pluralismo entre as correntes profissionais democráticas.

O Serviço Social, ao adotar uma visão de totalidade para a leitura e análise da realidade e ao firmar esse compromisso com a classe trabalhadora, não se refere apenas àquela pertencente à zona urbana; outrossim, a zona rural é e faz parte da classe trabaIhadora pertencente ao público-alvo dessa profissão.

\section{COMPETÊNCIAS E ATRIBUIÇÕES DO SERVIÇO SOCIAL NA ATER}

O Serviço Social, a partir do momento que adota como perspectiva o método histórico-crítico dialético e se posiciona a favor da justiça social e da emancipação da classe trabalhadora, precisa ter em mente que suas ações, desenvolvidas em qualquer espaço

11 O Código de Ética de 1986 foi elaborado com o intuito de ampliar as conquistas profissionais e adquirir bases consistentes para o exercício do fazer profissional, pois os códigos anteriores não refletiam os interesses da categoria nem as exigências da sociedade brasileira. Contudo, apesar de se tratar de um avanço, tal código demonstrou certa fragilidade de operacionalização, visto que afirma compromisso com a classe trabalhadora, mas não estabelece uma mediação com os valores éticos. Diante disso, fez-se necessária a criação do atual Código de Ética. 


\section{temporalis}

sócio-ocupacional que seja, devem ser guiadas pelas propostas estabelecidas no Projeto Ético-Político da profissão.

Portanto, vale salientar que o/a assistente social, mesmo sendo denominado/a como extensionista rural, ao se inserir na Assistência Técnica e Extensão Rural, deverá ter clareza de quais as competências e atribuições que lhe cabem. Essas competências e atribuições ${ }^{12}$ estão estabelecidas na Lei de Regulamentação da profissão (Lei n. 8.662, de 07 de junho de 1993), em seus Artigos $4^{\circ}$ e $5^{\circ}$, respectivamente, e serão apresentadas através do que se denominou, aqui, de linhas de atuação. Assim, para uma melhor compreensão dessas possíveis linhas de atuação, serão apontadas algumas que dizem respeito às competências e outras que se relacionam às atribuições privativas do/a assistente social, conforme a análise desta autora.

\section{LINHAS DE ATUAÇÃO RELACIONADAS ÀS COMPETÊNCIAS}

\section{Políticas Públicas, Interdisciplinaridade e Intersetorialidade}

Baseado no Art. $6^{\circ}$ da Constituição Federal, o qual afirma que são direitos sociais a educação, a saúde, a alimentação, o trabalho, a moradia, o lazer, a segurança, a previdência social, a proteção à maternidade e à infância, bem como a assistência aos desamparados, afirma-se que o acesso a políticas públicas que garantam a efetivação desses direitos não somente aos/às trabalhadores/as urbanos/as, como também aos rurais, torna-se imprescindível.

Diante disso, defende-se que a interdisciplinaridade e a intersetorialidade podem tratar-se de relevantes instrumentos para se alcançar tal objetivo. Vale ressaltar que o/a assistente social é um dos profissionais da ATER que mais têm facilidade em participar de ações interdisciplinares, visto que, enquanto muitos possuem uma formação tecnicista e especializada, ele apresenta uma formação generalista, já que muitas faculdades de Serviço Social adotam uma grade curricular ampla e com enfoque crítico.

12 Enquanto que as competências cabem a qualquer profissional que tenha capacidade em executar alguma da tarefa, as atribuições são privativas a determinado/a profissional. 
A formação acadêmica e os objetivos da profissão também permitem que o/a assistente social se destaque em relação ao desenvolvimento de ações intersetoriais. Através de atendimento e encaminhamento de demandas e da articulação entre as políticas públicas, esse/a extensionista rural poderá estabelecer parcerias com instituições de setores do poder público (Secretarias Municipais, Conselho Tutelar, Unidades de Saúde, Escolas etc.) e poder intervir em determinadas problemáticas.

Portanto, pode-se afirmar que o/a assistente social na ATER não somente poderá trabalhar articulando as várias políticas públicas, mas também poderá planejar, executar e avaliar as políticas que são geridas pelas instituições de ATER. A respeito de políticas e programas adotados pela EMATER/AL, pode-se afirmar que, dentre os convênios que foram/serão desenvolvidos por esta, estão: Mulheres Rurais; Produção Agroecológica Integrada e Sustentável (PAIS); Agricultura Urbana e Periurbana (AUP); Programa de Aquisição de Alimentos (PAA) - Modalidade Especial Leite; Seguro Garantia Safra: 2010/11; Programa de Aquisição de Alimentos (PAA) - Compra Direta com Doação Simultânea e Programa de Dinamização Produtiva.

Posto isso, destaca-se, aqui, o PAA, modalidade Compra Direta e Doação Simultânea, já que se acredita que se refere a um dos mais interessantes programas e mais eficientes, visto que ele não apenas disponibiliza um novo mercado para escoamento dos alimentos da agricultura familiar, como também aproxima rural e urbano, que são beneficiários de tal programa. Contudo, há que se considerar que isso somente se realizará se o programa for apoiado pelo município e gerido por uma equipe interdisciplinar, a qual, além de assistir os/as agricultores/as familiares cadastrados/as e os beneficiários/as, envolva todos/as em um processo participativo.

\section{Cooperativismo, Associativismo e Grupos Produtivos de Mulheres}

Uma das práticas mais desenvolvidas e estimuladas na ATER é a que envolve a assistência às cooperativas, às associações e aos grupos produtivos de mulheres. 


\section{temporalis}

A imagem do Serviço Social, quando inserido nesse espaço, muitas vezes é associada a tais temáticas, o que nos leva a indagar se o estímulo a essas ações, principalmente as relacionadas aos grupos produtivos de mulheres, não incentiva a renovação de práticas conservadoras que eram desenvolvidas pela profissão em sua gênese: os trabalhos com grupos tinha como objetivo ajustar o sujeito e, consequentemente, fortalecer os interesses capitalistas.

Contudo, como o objeto deste estudo não é especificamente esse, deixar-se-á essa indagação em aberto para que se debata em uma nova pesquisa, expondo aqui as possíveis intervenções do/a extensionista rural.

Baseando-se em observações de experiências exitosas, constatadas tanto no ambiente de trabalho quanto por meio de referências bibliográficas, pode-se afirmar que as ações e atividades desenvolvidas com cooperativas, associações e grupos produtivos de mulheres podem criar um canal que promova não apenas a socialização de informações acerca da própria gestão desses (competências e atribuições dos membros, estatutos e documentos, financiamento, comercialização etc.), como também de sensibilização para efetivação de direitos (sociais, humanos, políticos etc.), por meio da disseminação da própria informação de que esses/as agricultores/as familiares têm tal/tais direitos e da apresentação de formas de organização.

\section{Controle Social e Metodologia Participativa}

As transformações no cenário político, social, cultural e econômico no Brasil tiveram como uma de suas consequências a criação da Constituição Federal de 1988, que garante não apenas os direitos sociais dos/as trabalhadores/as, sendo eles/as urbanos/as ou rurais, como também impulsiona a descentralização nas decisões políticas e a participação social.

O processo de participação da sociedade faz-se relevante no processo decisório em relação ao planejamento, execução e avaliação das políticas públicas. Portanto, afirma-se que isso não se difere quando se trata da gestão da Política Nacional de Assistência Técnica e Extensão Rural, bem como dos serviços de 
ATER. O protagonismo dos/as agricultores/as familiares precisa ser estimulado e cabe ao/à extensionista rural colaborar nesse processo, que se realiza desde a promoção de ações que adotem a metodologia participativa até o incentivo à efetivação do Controle Social.

A metodologia participativa tem grande valia no processo de conhecimento da realidade, de organização das ações e da gestão social, bem como na execução e avaliação dessas ações. Ao adotar tal metodologia, o/a profissional poderá promover a troca de conhecimentos, entre extensionistas e agricultores/as familiares, que atingirão não somente o alcance dos processos antes citados, como também aproximarão tais sujeitos. Vale ressaltar que dentre as técnicas adotadas aqui está a realização do Diagnóstico Rural Participativo (DRP), que é composto por um conjunto de ferramentas e de Dinâmicas de Grupo.

Em relação à participação popular através do Controle Social, mesmo diante de limites e contradições, o seu exercício precisa ser estimulado pelo/a extensionista rural, sobretudo pelo Serviço Social, que, além de ter ciência de tal importância, é uma/ um das/os profissionais que mais têm debatido e defendido isso. Contudo, conforme afirma Souza (2010, p. 74), é preciso não somente "entender os fundamentos que explicam o controle social, a dinâmica do capital e a relação de subordinação do trabalho", como também saber que "o controle social pelo trabalho supõe, portanto, a efetividade de seu projeto revolucionário através do fortalecimento das lutas sociais que enfrentem os determinantes estruturais do capital".

\section{Assessoria e Consultoria a Movimentos Sociais do Campo}

Segundo Matos (2009, s/p), "a distinção entre assessoria e consultoria é mínima. Consultoria vem da palavra consultar, que significa pedir opinião. Portanto, consultoria é mais pontual que assessoria, que remete a ideia de assistir". "É somente a partir da clareza teórico-política da proposta de assessoria, da pesquisa sobre a instituição ou dos movimentos sociais, ou da vida dos usuários de algum serviço que os profissionais de Serviço Social poderão iniciar o processo de assessoria e consultoria [...]". 


\section{temporalis}

Compete ao Serviço Social, como estabelece o Art. $4^{\circ}$, em seu inciso IX, da Lei de Regulamentação da profissão, "prestar assessoria e apoio aos movimentos sociais em matéria relacionada às políticas sociais, no exercício e na defesa dos direitos civis, políticos e sociais da coletividade".

[...] faz-se necessário potencializar propostas de fortalecimento dos movimentos sociais calcadas na perspectiva contrária à sociabilidade do capital, objetivando a viabilização prático-política do projeto profissional. Nesta pesquisa, têm-se o exemplo significativo das práticas de assessoria aos movimentos sociais, instrumentalizando-fortalecendo-capacitando distintos sujeitos coletivos em sua luta cotidiana (MORO; MARQUES, 2011, p. 42).

Portanto, o/a assistente social, no âmbito da ATER, poderá assessorar e/ou desenvolver consultoria a movimentos sociais do campo, como o Movimento dos Trabalhadores Rurais Sem Terra (MST), a Comissão Pastoral da Terra (CPT), o Movimento das Mulheres Camponesas (MMC), dentre outros.

\section{LINHAS DE ATUAÇÃO EM RELAÇÃO ÀS ATRIBUIÇÕES PRIVATIVAS DO/A ASSISTENTE SOCIAL}

\section{Assessoria e Consultoria sobre o Serviço Social na ATER}

A assessoria e/ou consultoria também pode/m ser prestada/s por profissionais do Serviço Social, que possuem experiência e/ou desenvolvem estudos acerca das questões agrárias e das possíveis práticas do Serviço Social na ATER, a assistentes sociais que se encontram inseridos nesse âmbito.

De acordo com Matos (2009, s/p), que se baseou no que foi afirmado por Vasconcelos (1998), a assessoria pode se realizar através da disciplina Estágio Supervisionado, a qual aproximará a academia do meio profissional, tornando, dessa forma, mais fácil relacionar teoria e prática tanto nas intervenções dos/as profissionais acadêmicos quanto dos/as que se encontram inseridos/as nos demais espaços sócio-ocupacionais; "é no trabalho de supervisão que os docentes envolvidos tomam contato com a realidade institucional e, a partir daí, podem pensá-la e problematizá-la. 
E também nesse processo é possível ao assistente social tomar contato (e interagir) com o debate posto na Academia".

Portanto, afirma-se que "o assessor, na sua privilegiada posição de agente externo e a partir da sua capacidade profissional, pode contribuir apontando caminhos e auxiliando na desvelação de questões que a equipe e o profissional, sozinhos, não podem identificar" (MATOS, 2009, s/p).

\section{Supervisão de Estagiários/as de Serviço Social}

Conforme as Diretrizes Curriculares do Serviço Social, a formação profissional deve capacitar teórico-metodologicamente e ético-politicamente os/as futuros profissionais, pois são requisitos indispensáveis para o exercício de atividades técnico-operativas.

Assim sendo, com base nessa afirmação e nos princípios que essas diretrizes apontam como sendo da formação profissional, sobretudo, o que afirma que a indissociabilidade da supervisão acadêmica e profissional na atividade de estágio é necessária, assegura-se que o estágio é obrigatório para os/as discentes do Serviço Social.

Diante disso, apresenta-se a supervisão de estagiários/as de Serviço Social como uma das atribuições do/a assistente social também quando se está inserido/a na ATER. A supervisão de estagiários/as, dependendo do comprometimento dos/as discentes, da supervisão acadêmica e da própria supervisão de campo, poderá promover a troca de saberes, além da relação teoria e prática e da apreensão da realidade, para melhor intervir nas expressões da questão social.

\section{Estudo ou Perícia Social: Informação Técnica, Relatório, Laudo e Parecer Social}

A realização do estudo ou perícia social cabe somente ao profissional do Serviço Social, visto que a Lei de Regulamentação, em seu Art. $4^{\circ}$, afirma que realizar vistorias, perícias técnicas, laudos periciais, informações e pareceres sobre a matéria de Serviço Social são atribuições somente desses/as profissionais.

De acordo com Fávero (2009, s/p), o estudo, também denominado perícia social, é solicitado por um juiz, que nomeará um 


\section{temporalis}

perito, que, nesse caso, será um/a assistente social. A solicitação por essa perícia tem a finalidade de oferecer elementos para decisão judicial. "No meio judiciário, o estudo e/ou perícia social pode ser realizado por assistente social servidor da instituição, por servidor de outro órgão da Administração Pública estadual ou municipal [...] e por perito ou assistente técnico, evidentemente, com formação na área".

Portanto, nada impede que o/a assistente social que está inserido/a na ATER seja nomeado/a como perito social. Assim, para realizar o estudo social e, posteriormente, emitir um parecer, cabe a esse/a profissional a escolha de que instrumentos ele/a se utilizará para o conhecimento da realidade e que registros irá elaborar para que sejam integrados aos autos processuais.

Denomina-se informe ou informação técnica, o documento que relata, geralmente de maneira breve, alguma informação inicial ou complementar relacionada à ação processual, o que pode variar dependendo da dinâmica de cada espaço de trabalho e/ou instância judiciária. O relatório social, por sua vez, apresenta de maneira descritiva e interpretativa o registro de uma ou mais entrevistas, iniciais ou de acompanhamento. Esse documento também pode ser mais detalhado, dando conta de uma entrevista aprofundada, de maneira a registrar os aspectos do caso pertinentes à área de atuação do Serviço Social. [...] O laudo é o registro que documenta as informações significativas, recolhida por meio do estudo social, permeado ou finalizado com interpretação e análise. Em sua parte final, via de regra, registra-se o parecer conclusivo, do ponto de vista do Serviço Social. [...] O parecer social sintetiza a situação, apresenta uma breve análise e aponta conclusões ou indicativos de alternativas, que irão expressar o posicionamento profissional frente ao objeto de estudo (FÁVERO, 2009, s/p).

Diante disso, assegura-se que a atuação do/a assistente social na ATER é muito mais ampla do que se imagina e que esse/a profissional poderá contribuir para realização de atividades interdisciplinares e intersetoriais, assim como estimular o processo de participação dos/as trabalhadores/as rurais através do Controle 
Social. Sua formação generalista, baseada em um Projeto ÉticoPolítico Profissional, que almeja uma nova ordem societária, Ihe revela dimensões (ético-políticas, teórico-metodológicas e técnico-operativas) relevantes para a leitura da realidade e para realização de intervenções que garantam a efetivação de direitos sociais, políticos, culturais, humanos e econômicos.

Desse modo, há de se considerar o caráter de educador/a não formal e a afinidade que a profissional tem com ações socioeducativas. Suas práticas devem ter como objetivo principal o fortalecimento da autonomia dos homens e mulheres do campo, de forma que a produtividade e a lucratividade não sejam os principais motivos de suas ações; deve-se pensar, primeiramente, na qualidade de vida da população usuária dos serviços.

\section{CONSIDERAÇÕES FINAIS}

O rural brasileiro não é o que muitos pensam: o lugar do atraso, onde as atividades são predominantemente agrícolas e seus sujeitos precisam das políticas públicas desenvolvidas somente para o campo.

Esse rural não deve e não precisa se moldar aos costumes urbanos; ele é possuidor de direitos sociais, políticos, culturais, humanos e econômicos assegurados a qualquer cidadão/cidadã. Desse modo, deve ter acesso a políticas públicas como a da saúde, educação, previdência e assistência social.

No entanto, sabe-se que as políticas sociais brasileiras têm sido orientadas pelo ideário neoliberal e as condições para efetivação dessas são mínimas. A esse respeito, pode-se citar a Política Nacional de Assistência Técnica e Extensão Rural, que, apesar de já ter mais de uma década que fora idealizada, atravessa, ainda, velhas problemáticas. Os serviços de ATER têm-se reduzido ao cumprimento de metas de chamadas públicas ou a atendimentos mediatos e assistências descontínuas, visto que seu quadro de extensionistas rurais, pelo menos no caso de Alagoas, se resume a poucos/as funcionários/as efetivos/as e a bolsistas que atuam por um período de no máximo dois anos.

Contudo, apesar de também se constatar a presença de práticas conservadoras nesse âmbito e de se correr o risco de estas 


\section{temporalis}

disseminarem a falsa ideia de que o desenvolvimento sustentável é aquele relacionado somente ao econômico, há que se considerar que a ATER, apesar dos impasses, vem atravessando um novo momento: a PNATER assegura que seu público é o pequeno agricultor e suas ações devem privilegiar a participação e a qualidade de vida dos/as trabalhadores/as rurais.

Posto isso, percebe-se que, além da atenção do governo a essa política, é relevante o trabalho interdisciplinar e intersetorial para sua efetivação. Assim, pode-se reafirmar que por ter uma formação profissional generalista e ter claramente estabelecidas suas competências e atribuições na Lei de Regulamentação da profissão, o/a assistente social, inserido/a na ATER, poderá desenvolver ações sob diversas linhas de atuação, as quais não deverão limitar-se somente ao trabalho com grupos produtivos e à socialização de informações acerca de créditos rurais.

\section{REFERÊNCIAS}

ASSISTÊNCIA TÉCNICA E EXTENSÃO RURAL. Brasília: Associação Especial de Gênero, Raça e Etnia/MDA.

BARROCO, M. L. S. Ética e Serviço Social: fundamentos ontológicos. 4. ed. São Paulo: Cortez, 2006. p. 141-208.

BRASIL. Lei n. 8.662, de 7 de junho de 1993. Dispõe sobre a profissão de Assistente Social e dá outras providências. Disponível em: <http://www.cfess.org.br/arquivos/L8662.pdf>. Acesso em: 15 dez. 2014.

BRASIL. Lei n. 12.188, de 11 de janeiro de 2010. Institui a Política Nacional de Assistência Técnica e Extensão Rural para a Agricultura Familiar e Reforma Agrária - PNATER e o Programa Nacional de Assistência Técnica e Extensão Rural na Agricultura Familiar e na Reforma Agrária - PRONATER, altera a Lei n. 8666, de 21 de junho de 1993, e dá outras providências. Disponível em: <http://www. planalto.gov.br/ccivil_03/Ato2007-2010/2010/Lei/L12188.htm>. Acesso em: $20 \mathrm{dez} .2013$.

BRAVO, M. I. S. Serviço Social e Reforma Sanitária: lutas sociais e práticas profissionais. 2. ed. São Paulo: Cortez, 2007. p. 37-148. 
BRAZ, M. Notas Sobre o Projeto Ético-Político. Assistente Social: ética e direitos. 3. ed. atual. Rio de Janeiro: CRESS, 2001. (Coletânea de leis e resoluções).

CAPORAL, F. R. Política Nacional de Ater: primeiros passos de sua implementação e alguns obstáculos e desafios a serem enfrentados. Brasília, 14 ago. 2005. Disponível em: <http://agroeco.org/ socla/wpcontent/uploads/2013/11/Pnater+primeiros+passos+....+ Caporal>. Acesso em: 16 jan. 2014.

CAPORAL, F. R.; RAMOS, L. F. Da Extensão Rural Convencional à Extensão Rural para o Desenvolvimento Sustentável: enfrentar desafios para romper a inércia. Brasília, setembro de 2006. (Texto em fase de publicação).

CASSEL, G. Nova Lei de ATER. Brasília, jan. 2010. Entrevista concedida ao Portal do MDA. Disponível em: <http://portal.mda.gov. br/portal/saf/noticias/item?item_id=3482486>. Acesso em: $16 \mathrm{fev}$. 2014.

CAZELLA, A. A.; KREUTZ, I. J.; PINHEIRO, S. L. G. A construção de novas atribuições para a Assistência Técnica e Extensão Rural: a mediação com reconhecimento da identidade. Santa Maria: UFSM, janeiro/dezembro de 2005. Disponível em: <http://w3.ufsm.br/extensaorural/art2ed12.pdf>. Acesso em: 10 dez. 2013.

CRUZ, S. S. O fenômeno da pluriatividade no meio rural: atividade agrícola de base familiar. Revista Serviço Social \& Sociedade, São Paulo, n. 110, p. 241-269, abr./jun. 2012.

DAL MORO, M.; SOARES, M. M. A Relação do Serviço Social com os Movimentos Sociais na Contemporaneidade. Revista Temporalis, Brasília, v. 21, p. 13-47, 2011.

DIAS, M. M. Extensão Rural para Agricultores Assentados: uma Análise das Boas Intenções Propostas pelo "Serviço de Ates". Cadernos de Ciência \& Tecnologia, Brasília, v. 21, n. 3, p. 499-543, 2004 . 


\section{temporalis}

ENGELBRECHT, M. R. Desenvolvimento do Capitalismo no Campo: as Transformações do Trabalhador rural em proletariado agrícola. In: SANT'ANA, Raquel Santos; CARMO, Onilda Alves; LOURENÇO, Edvânia Ângela de Souza (Org.). Questão agrária e saúde do trabaIhador: desafios para o século XXI. São Paulo: Cultura Acadêmica, 2011. p. 39-47.

FÁVERO, E. T. Instruções sociais de processos, sentenças e decisões. In: CFESS, Conselho Federal de Serviço Social; ABEPSS, Associação Brasileira de Ensino e Pesquisa em Serviço Social. Serviço Social: direitos sociais e competências profissionais. Brasília: CFESS/ABEPSS, 2009.

GALINDO, W. C. M. Intervenção Rural e Autonomia: a experiência da Articulação no Semiárido/ASA em Pernambuco. 2003. Dissertação (Mestrado em Sociologia) - Programa de Pósgraduação em Sociologia, Universidade Federal de Pernambuco, Recife, 2003.

GOHN, M. G. Educação não formal e o educador social: atual no desenvolvimento de projetos sociais. São Paulo: Cortez, 2010. (Coleção questões da nossa época; v. 1).

GORENDER, J. Gênese e Desenvolvimento do Capitalismo no Campo. In: STEDILE, João Pedro. Questão Agrária no Brasil: o Debate na Década de 1990. São Paulo: Expressão Popular, 2013. p. 19-53.

LUSA et al. Política Nacional de Assistência Técnica e Extensão Rural e Serviço Social: o Campo como Desafio. Cadernos Ceru, São Paulo, v. 24, n. 1, p. 115-135, 29 nov. 2013. Disponível em: <http:// www.revistas.usp.br/ceru/article/view/72031/75275>. Acesso em: 19 fev. 2014.

\section{LUSA, M. G. A (in)visibilidade do Brasil rural no Serviço Social: o} reconhecimento dos determinantes a partir da análise da mediação entre a formação e o exercício profissional em Alagoas. 2012. Tese (Doutorado em Serviço Social) - Pontifícia Universidade Católica de São Paulo, São Paulo, 2012. 
LUSTOSA, Maria das Graças Osório P. Reforma Agrária à Brasileira: política social e pobreza. São Paulo: Cortez, 2012.

MATOS, M. C. Assessoria, consultoria, auditoria e supervisão técnica. In: CFESS, Conselho Federal de Serviço Social; ABEPSS, Associação Brasileira de Ensino e Pesquisa em Serviço Social. Serviço Social: direitos sociais e competências profissionais. Brasília: CFESS/ABEPSS, 2009.

MDA. Política Nacional de Assistência Técnica e Extensão Rural, 2004. Disponível em: <http://comunidades.mda.gov.br/portal/ saf/arquivos/view/ater/Pnater.pdf $>$. Acesso em: 18 jan. 2014.

NETTO, J. P. Ditadura e Serviço Social: uma análise do serviço social no Brasil pós-64. 10. ed. São Paulo: Cortez, 2007. p. 165-202.

. O Serviço Social e a Tradição Marxista. Serviço Social \& Sociedade, São Paulo, ano X, n. 30, abr. 1989.

PEIXOTO, M. Extensão Rural no Brasil: uma abordagem histórica da legislação. [Textos para discussão, n. 48] Brasília: Consultoria Legislativa do Senado Federal - Centro de Estudos, outubro/2008. Disponível em: <http://www.senado.gov.br/senado/ conleg/textos_discussao/TD48-MarcosPeixoto.pdf>. Acesso em: 20 jan. 2014 .

SOUZA, R. M. Controle Social e Reprodução Capitalista: Polêmicas e Estratégias Contemporâneas. Revista Temporalis, Brasília, ano 10, n. 20, p. 49-76, jul./dez. 2010. Disponível em: <http://periodicos. ufes.br/temporalis/article/view/3448>. Acesso em: 12 fev. 2014.

VASCONCELOS, E. M. Serviço Social e Interdisciplinaridade: o exemplo da saúde mental. Serviço Social \& Sociedade, São Paulo: Cortez, ano XVIII, n. 54, julho de 1997. 